\title{
Safety of neurolytic erector spinae plane blocks for cancer pain
}

\author{
Abdelghafour Elkoundi, MD (1) - Noureddine Kartite, MD • Nawfal Doghmi, PhD • \\ Abdelouahed Baite, PhD
}

Received: 2 April 2020/Revised: 2 April 2020/Accepted: 3 April 2020/Published online: 21 May 2020

(C) Canadian Anesthesiologists' Society 2020

\section{To the Editor,}

Phenol is often used as a neurolytic agent to treat cancer-related pain. At the concentrations most commonly used, phenol can cause indiscriminate damage to both large and small motor and sensory axons. In a recent report in the Journal, Papa et al. ${ }^{1}$ performed an ultrasound-guided neurolytic (8\% phenol) erector spinae plane (ESP) block to treat cancer-related shoulder pain. The choice of this technique over a cervical epidural or a brachial plexus block was rationalized using cost considerations, its simpler performance, and easier ambulatory management. Papa et al. documented both improved analgesia and quality of life in their patient. ${ }^{1}$ The main risk that the authors outlined related to the possible extension of the neurolytic solution into the epidural space; this was avoided by using slow fractional injections.

The use of a phenol neurolytic block of other nerves has been widely reported, including some of its complications. For example, Bodine-Fowler et al. ${ }^{2}$ examined the effects of a 5\% phenol-induced nerve block on the morphology of the sciatic nerve and selected muscles distal to the lesion at various time points (from two days to five months). The results of that study suggested that phenol may produce a very severe injury (i.e., more severe than a crush injury).

Editor's Note: The authors of the article: Can J Anesth 2020; DOI: https://doi.org/10.1007/s12630-020-01633-4 did not submit a reply to the above letter.

A. Elkoundi, MD $(\bowtie) \cdot$ N. Kartite, MD · N. Doghmi, PhD .

A. Baite, $\mathrm{PhD}$

Department of Anesthesiology and Critical Care, Military

Teaching Hospital Mohammed V, Faculty of Medicine and

Pharmacy of Rabat, Mohammed V University of Rabat, Rabat,

Morocco

e-mail: abd.el.koundi@gmail.com
Those authors concluded that the use of phenol (concentrations $\geq 5 \%$ ) can lead to permanent muscle weakness; thus, it should not be used if only a temporary block is desired. As the phenol concentration used by Papa et al. was much higher, we are concerned about the longterm implications of possible paraspinal muscle atrophy. The spread of the solution used in ESP block is unpredictable and can affect the dorsal rami of the spinal nerves in an extensive multilevel way. ${ }^{3,4}$

Thus, erector spinae muscle denervation might adversely impact its function as a stabilizer of the vertebral column and cranio-cervical region, and impair the maintenance of spinal balance and global alignment. ${ }^{5}$ These other outcomes should be studied in future studies before any definitive conclusions about the safety of neurolytic ESP block are drawn.

Conflict of interest None.

Funding statement None.

Editorial responsibility This submission was handled by Dr. Hilary P. Grocott, Editor-in-Chief, Canadian Journal of Anesthesia.

\section{References}

1. Papa P, Antunez-Maciel M, Asenjo JF. Cancer shoulder pain treated with a neurolytic erector spinae plane block. Can J Anesth. 2020. DOI: https://doi.org/10.1007/s12630-020-01633-4.

2. Bodine-Fowler SC, Allsing S, Botte MJ. Time course of muscle atrophy and recovery following a phenol-induced nerve block. Muscle Nerve. 1996;19:497-504.

3. Hernandez-Porras BC, Rocha A, Juarez AM. Phenol spread in erector spinae plane block for cancer pain. Reg Anesth Pain Med. 2019. DOI: https://doi.org/10.1136/rapm-2019-100509.

4. Schwartzmann A, Peng P, Maciel Antunez M, Forero M. Mechanism of the erector spinae plane block: insights from a 
magnetic resonance imaging study. Can J Anesth. 2018;65:11656.

5. He K, Head J, Mouchtouris N, et al. The implications of paraspinal muscle atrophy in low back pain, thoracolumbar pathology, and clinical outcomes after spine surgery: a review of the literature.
Global Spine J. 2019. DOI: https://doi.org/10.1177/ 2192568219879087.

Publisher's Note Springer Nature remains neutral with regard to jurisdictional claims in published maps and institutional affiliations. 